\title{
Meta-Analysis
}

\section{The difference between preserving and non-preserving left colonic artery for low rectal cancer: a meta-analysis}

\author{
Zakari Shaibu ${ }^{1,2}$, Zhihong Chen ${ }^{1 *}$
}

\begin{abstract}
${ }^{1}$ Department of Gastrointestinal Surgery, Affiliated and Peoples Hospital of Jiangsu University, Zhenjiang, Jiangsu, PRC China

${ }^{2}$ Oversea Education College, Jiangsu University, Zhenjiang, Jiangsu, PRC China
\end{abstract}

Received: 28 November 2020

Revised: 08 December 2020

Accepted: 15 December 2020

\section{*Correspondence:}

Dr. Zhihong Chen,

E-mail: chenzhi-hong@163.com

Copyright: () the author(s), publisher and licensee Medip Academy. This is an open-access article distributed under the terms of the Creative Commons Attribution Non-Commercial License, which permits unrestricted non-commercial use, distribution, and reproduction in any medium, provided the original work is properly cited.

\begin{abstract}
The aim of this study is to compare the superiority and safety of preserving and non-preserving left colonic artery. PubMed, Google scholar and Medline were searched for eligible studies from1965 to 2018. Operative time, blood loss, number of resected lymph nodes, anastomotic leakage, and ileus, and morbidity, hospital length of stay, wound infection and mortality were the main outcome study. 23 studies involving 10,644 patients were included in the analyses. Compared with the preserving approach, the non-preserving approach had less operative time (weighted mean difference $(\mathrm{WMD})=9.37 \mathrm{~min}, 95 \%$ confidence interval $(\mathrm{CI})(8.92,9.81), \mathrm{p}<0.01)$, less blood loss $(\mathrm{WMD}=8.28,95 \% \mathrm{CI}$ $(7.43,9.13), \mathrm{p}<0.01)$, and preserving approach had shorter duration of hospital stay (WMD $=-2.84$ days, $95 \% \mathrm{CI}(-5.49$, $-0.19), \mathrm{p}<0.06)$ and also anastomotic leakage (WMD $=0.79,95 \%$ CI $(0.67,0.95), \mathrm{p}<0.54)$. No other significant differences were observed. Preserving left colonic artery proves to be safer and more feasible as compared to the nonpreserving left colonic artery in terms of reducing the incidence of anastomotic leakage and hospital length of stay. Non-preserving left colonic artery proved to have less operative time and blood loss, because most of the surgery was done laparoscopically.
\end{abstract}

Keywords: Preservation, Non-preservation, Low tie, High tie, Colorectal cancer, Neoplasm, Inferior mesenteric artery

\section{INTRODUCTION}

Remarkably, colorectal cancers (CRC) are accountable for about ten percent of all cancers worldwide, which hugely measures to hundreds of millions of people that are now affected. Moreover, it is the third most predominant cancer in men and second most in women. ${ }^{1}$ Left colonic and rectal cancers represent just under two thirds of all colorectal malignancies. $^{2}$ Resection of the tumor with sufficient margins and related mesentery, including the lymph nodes, remains the main modality of treatment of colorectal cancer.
Excision of the apical lymph node at the root of the inferior mesenteric artery (IMA) is understood to be obligatory for radical resection of rectal cancer since apical lymph node resection contributes to improve lymph node retrieval rates and the accuracy of tumor staging. ${ }^{3}$ Presently, most surgeons perform a high ligation of the IMA in rectal cancer patients to attain apical lymph node resection, a procedure in which the IMA is ligated at its origin and the blood supply to the distal colon depends entirely on the marginal artery that arises from the middle colic artery. Notwithstanding it being accepted, that the marginal artery is satisfactory for supporting the viability of the remaining colon. ${ }^{4,5}$ Several studies have actually shown that a high 
tie of the IMA suggestively reduces perfusion of the proximal limb. ${ }^{6-9}$ Nevertheless, the resulting insufficient collateral circulation has the potential risk of leading to severe colonic ischemia in some patients. ${ }^{10}$ It has been suggested that low ligation, which is defined as ligation below the origin of the left colic artery (LCA) might resolve this difference. ${ }^{9}$ Still, this alternative procedure may end in a diminished number of harvested lymph nodes while distorting lymph node staging, thereby negatively affecting post-operative treatment. Also, avoided metastases may occur in some patients. With the viewpoint of these concerns, it was recently recommended that lymph node dissection nearby the IMA with preservation of the LCA would yield superior results. ${ }^{11,12}$ Supposedly, this surgical method would offer a better anastomotic blood supply also guarantee adequate lymph node retrieval rates. Studies trying this hypothesis in practice are obviously lacking but are immediately needed in order to advance the research and progress of the technique.

The goal of this study is to reveal the difference between preserving and non-preserving left colonic artery in low rectal cancer in terms of dominance and safety.

\section{Left colic artery}

The left colic artery is a subdivision of the inferior mesenteric artery that runs to the left behind the peritoneum and in front of the psoas major muscle, and after a short, but variable, course divides into an ascending and a descending branch; the stem of the artery or its branches cross the left ureter and left internal spermatic vessels. The branches of the left colic artery anastomose with branches of the middle colic and sigmoid arteries and contribute to the formation of the marginal artery of Drummond, an arterial channel that supplies the large intestine. After completing its course, the left colic artery divides into its terminal branches; the ascending and descending branch.

\section{Ascending branch}

Courses superiorly, anterior to the left kidney and then enters the transverse mesocolon. In the area of the splenic flexure, the ascending branch of the left colic artery anastomoses with the left branch of the middle colic artery, which arises from the superior mesenteric artery. This anastomosis is called the arcade of Riolan, which signifies a direct communication between the superior and inferior mesenteric arteries. This communication is significant to provide collateral blood flow in the event of a stenosis and occlusion.

\section{Descending branch}

Courses laterally in the retroperitoneum towards the descending colon, where it anastomoses with one of the sigmoid arteries, thereby contributing to the formation of the marginal artery of Drummond. (Figure 9)

\section{METHODS}

\section{Search strategy}

Studies published in English between the years of 1962 to 2018, were searched in the databases of PubMed, Google scholar and Medline using the main search terms "preservation", "non-preservation", "low tie", "high tie", "colorectal cancer", "neoplasm", "inferior mesenteric artery". The search strategy differed per database by their different requirements. Additionally, relevant studies in the references of related articles were also screened.

\section{Inclusion and exclusion criteria}

\section{Studies with the following criteria were included}

The article language was restricted to English. Full text was available, and the compared outcomes contained at least one of the items mentioned below. If the same research team participated in multiple studies, only the study with the most comprehensive data was included. Patients underwent preserving or low tie and nonpreserving or high tie approach for reasons other than rectal cancer (example- colorectal cancer. sigmoid cancer). Preservation or non-preservation of the LCA as the only difference between the experimental group and the control group.

\section{Studies were excluded for the following reasons}

Data on the main outcomes were unavailable. Case report reviews, comment, non-English articles, meta-analysis, animal study.

\section{Data extraction and study quality assessment}

Data extraction was performed by using specially designed data extraction sheets. After we collected 23 full papers, which included the author, year, country, design and number of patients. The primary research outcomes of this meta-analysis were operation time, blood loss, number of resected lymph nodes, morbidity, anastomotic leakage, hospital stay, wound infection and mortality were all considered.

\section{Statistical analysis}

The meta-analysis was performed using the review manager software 5.3 that was provided by the Cochrane Collaboration. Continuous variables were pooled using the mean difference (MD) with a $95 \%$ confidence interval (95\% CI), and dichotomous variables were pooled using the odds ratio (OR) with a 95\% CI. Studies that reported only the median, range, and size of the trial, the means and standard deviations were calculated according to Hozo et al. ${ }^{13}$ Statistical heterogeneity was evaluated by $\mathrm{I}^{2}$, and it was considered to be high if the $\mathrm{I}^{2}$ statistic was greater than $50 \%$. The fixed effects model was used for studies with low or moderate statistical heterogeneity, and the random 
effects model was used for studies with high statistical heterogeneity.

\section{RESULTS}

\section{Selected studies}

Four hundred twenty studies were identified by the search strategy previously described (Figure 1). Thirty pertinent studies were found after reading the abstracts. Finally, twenty-three studies were considered eligible after they were found to fit the inclusion criteria upon reading the full text. Studies were made up of 18 retrospective cohorts, 2 prospective studies and 3 randomized control trial studies. The studies were from UK, Canada, New York, Sweden, Japan, China, and Korea. In total, 3116 patients underwent preserving approach $(\mathrm{n}=3116)$ and non- preserving approach $(\mathrm{n}=7528)$ (Table 1$)$.

\section{Operation time}

Nine studies 14-22 reported a significant difference of operative time between the NPLCA group compared to the PLCA (WMD=9.37 min, 95\% CI (8.92, 9.81), $\mathrm{p}<0.01)$. Less operative time was observed in the NPLCA group. A fixed effect model was used due to significant heterogeneity $\quad\left(\mathrm{p}<0.0001, \quad \mathrm{I}^{2}=78 \%\right)$ Heterogeneity:
$\mathrm{Chi}^{2}=35.86, \mathrm{df}=8(\mathrm{p}<0.0001) ; \mathrm{I}^{2}=78 \%$. Test for overall effect: $Z=41.26(\mathrm{p}<0.00001)$. (Figure 2)

\section{Blood loss}

Six studies reported a significant difference of blood loss between the NPLCA group compared to the PLCA $(\mathrm{WMD}=8.28,95 \%$ CI $(7.43,9.13), \mathrm{p}<0.01) .{ }^{15,18-22}$ Less blood loss was observed in the NPLCA group. A fixed effect model was used due to significant heterogeneity $\left(\mathrm{p}=0.25, \quad \mathrm{I}^{2}=24 \%\right) . \quad$ Heterogeneity: $\mathrm{Chi}^{2}=6.59, \quad \mathrm{df}=5$ $(p=0.25) ; I^{2}=24 \%$. Test for overall effect: $Z=19.10$ $(\mathrm{p}<0.00001)$. (Figure 3)

Two studies reported a significant difference of hospital length of stay between the NPLCA group compared to the PLCA (WMD=-2.84, 95\% CI (-5.49, -0.19), $\mathrm{p}=0.04) .{ }^{15,20}$ Less duration was observed in the PLCA group. A fixed effect model was used due to significant heterogeneity $\left(\mathrm{p}=0.04, \mathrm{I}^{2}=72 \%\right)$. Heterogeneity: $\mathrm{Chi}^{2}=3.61$, df $=1$ $(\mathrm{p}=0.06) ; \mathrm{I}^{2}=72 \%$. Test for overall effect: $\mathrm{Z}=2.10(\mathrm{p}=0.04)$. However, according to this analysis the PLCA having less hospital length of stay has nothing to with a laparoscopic or open technique. Therefore, preservation of the LCA during a laparoscopic or open rectal cancer resection does not affect the postoperative hospital stay.

Table 1: The basic characteristics of studies included in the meta-analysis.

\begin{tabular}{|c|c|c|c|c|}
\hline Authors & Year & Country & Design & No. of patient PLCA/NPLCA \\
\hline Rosi et $\mathbf{a l}^{36}$ & 1962 & - & Retrospective cohort & $154 / 137$ \\
\hline Grinnel et $\mathbf{a l}^{35}$ & 1965 & - & Retrospective cohort & $181 / 179$ \\
\hline Corder et al ${ }^{6}$ & 1992 & UK & Retrospective cohort & $52 / 91$ \\
\hline Pezim et al $^{23}$ & 1994 & Canada & Retrospective cohort & $784 / 586$ \\
\hline Slanetz et $\mathbf{a l}^{30}$ & 1997 & $\mathrm{Ny}$ & Retrospective cohort & $1154 / 1107$ \\
\hline Adachi et $\mathbf{a l}^{34}$ & 1998 & Japan & Retrospective cohort & $38 / 134$ \\
\hline Komen et al ${ }^{16}$ & 2011 & Netherland & Prospective cohort & $17 / 16$ \\
\hline Hinoi et al ${ }^{15}$ & 2013 & Japan & Retrospective cohort & $155 / 256$ \\
\hline Han et $\mathbf{a l}^{26}$ & 2013 & China & Retrospective cohort & $80 / 76$ \\
\hline Rutegard et al $^{29}$ & 2012 & Sweden & Retrospective cohort & $1101 / 818$ \\
\hline Shen et al ${ }^{19}$ & 2014 & China & Retrospective cohort & $72 / 41$ \\
\hline Yamamoto et $\mathrm{al}^{20}$ & 2014 & Japan & Retrospective cohort & $70 / 43$ \\
\hline Matsuda et al ${ }^{18}$ & 2015 & Japan & RCT & $49 / 51$ \\
\hline Bostrom et al ${ }^{25}$ & 2015 & Sweden & Retrospective cohort & $388 / 334$ \\
\hline Zhang et $\mathbf{a l}^{21}$ & 2016 & China & Retrospective cohort & $132 / 84$ \\
\hline Rutegard et al ${ }^{28}$ & 2016 & Sweden & Prospective cohort & $18 / 5$ \\
\hline Yasuda et al $^{24}$ & 2016 & Japan & Retrospective cohort & $147 / 42$ \\
\hline Zedan et $\mathbf{a l}^{33}$ & 2016 & & Retrospective studies & $76 / 38$ \\
\hline Wang et $\mathbf{a l}^{32}$ & 2015 & China & RCT & $65 / 63$ \\
\hline Guo et $\mathbf{a l}^{48}$ & 2017 & China & RCT & $28 / 29$ \\
\hline Luo et $\mathrm{al}^{22}$ & 2017 & China & Retrospective cohort & $203 / 320$ \\
\hline Kverneng et $\mathrm{al}^{27}$ & 2017 & Sweden & Retrospective cohort & $432 / 373$ \\
\hline Lee et $\mathbf{a l}^{17}$ & 2018 & Korea & Retrospective cohort & $83 / 51$ \\
\hline
\end{tabular}




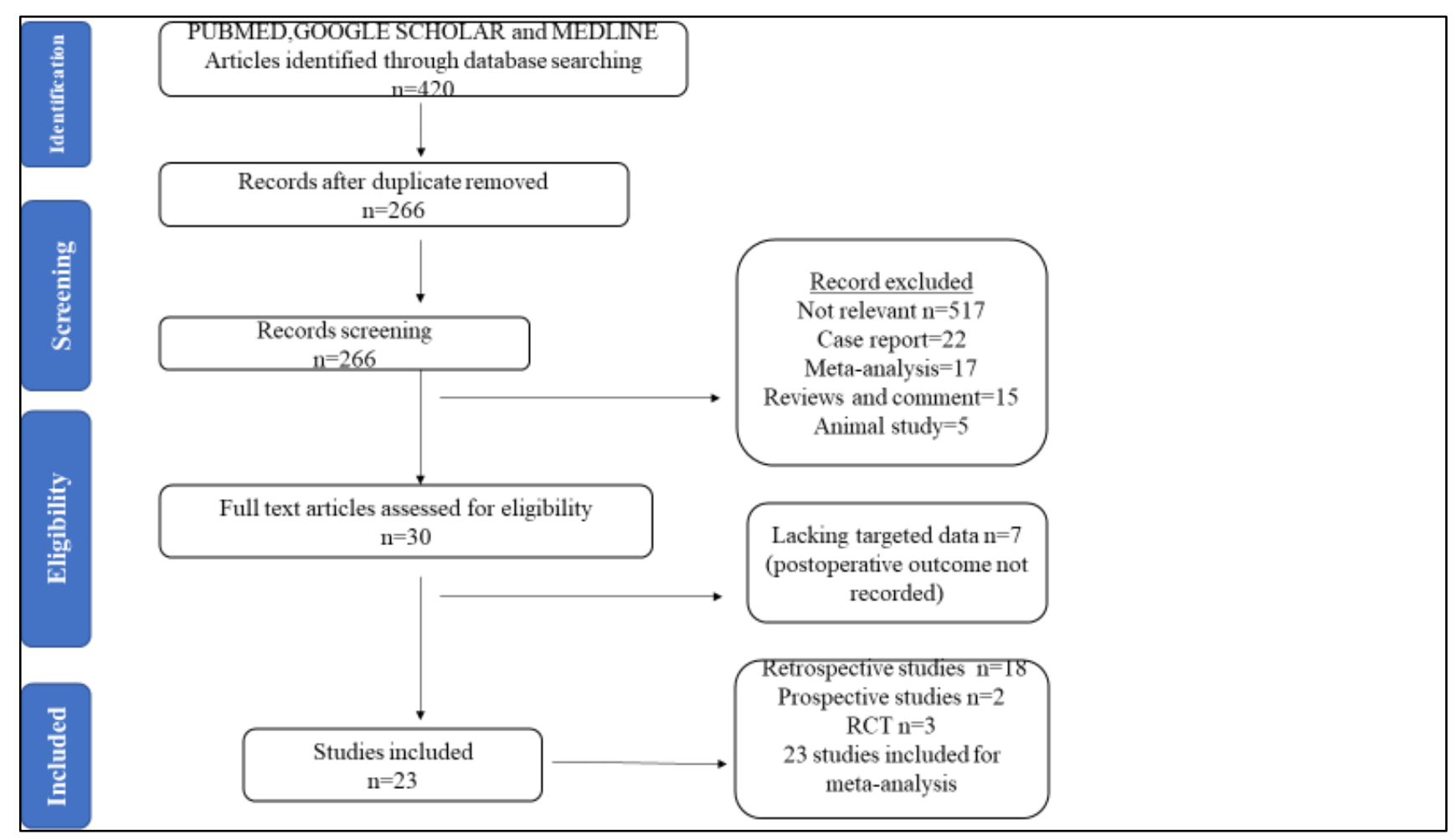

Figure 1: Flow chart showing the process for selecting the included studies.

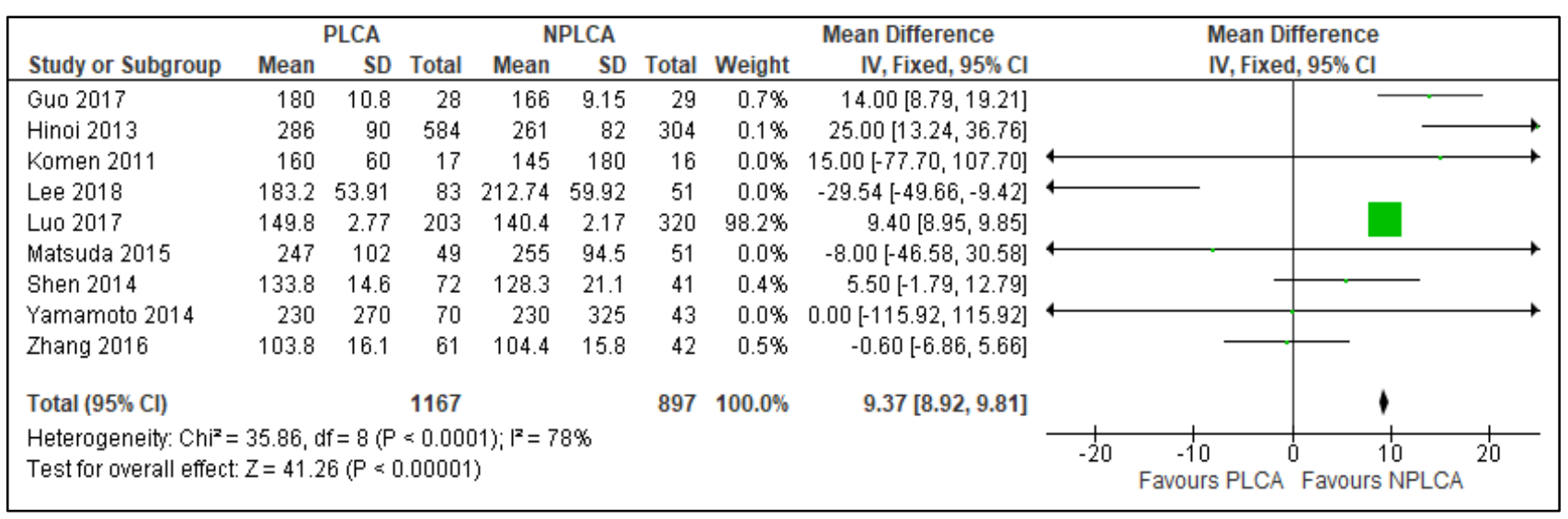

Figure 2: Preserved left colonic artery group versus non preserved left colonic artery, outcome. Operation time (min).

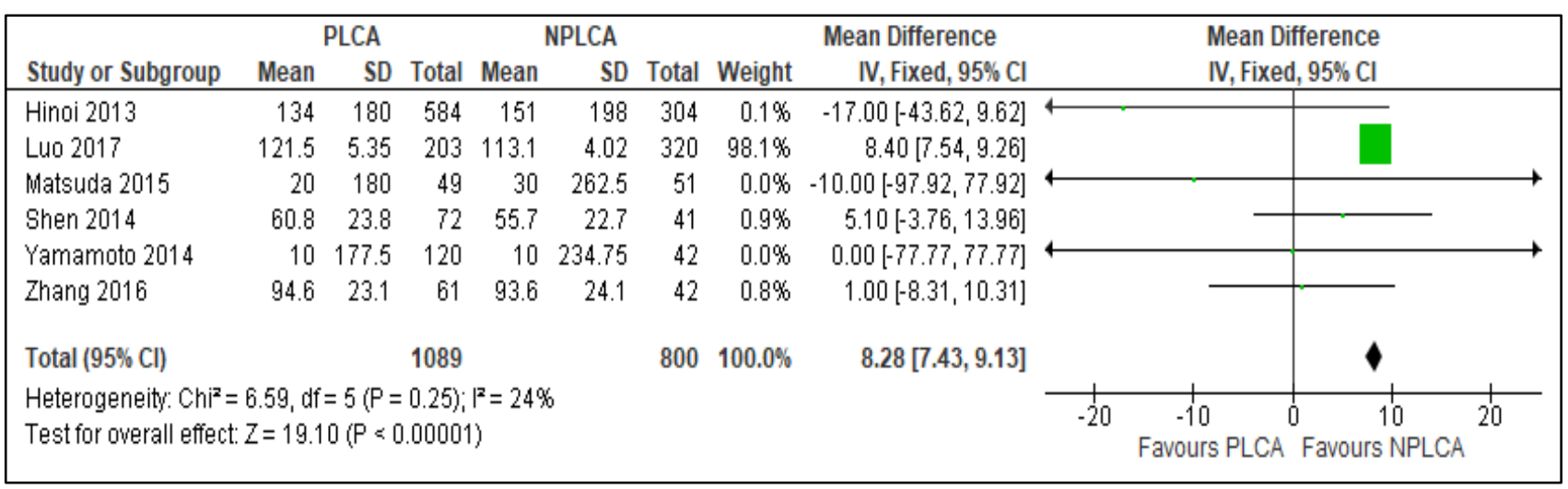

Figure 3: Preserved left colonic artery group versus non preserved left colonic artery, outcome: Blood loss (mL). 


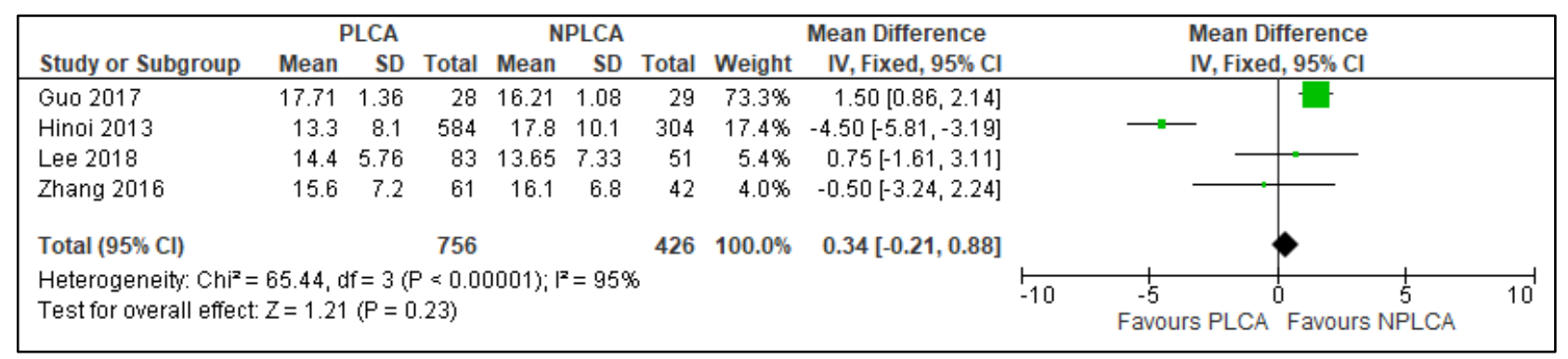

Figure 4: Preserved left colonic artery group versus non-preserved left colonic artery, outcome: lymph node Harvested.

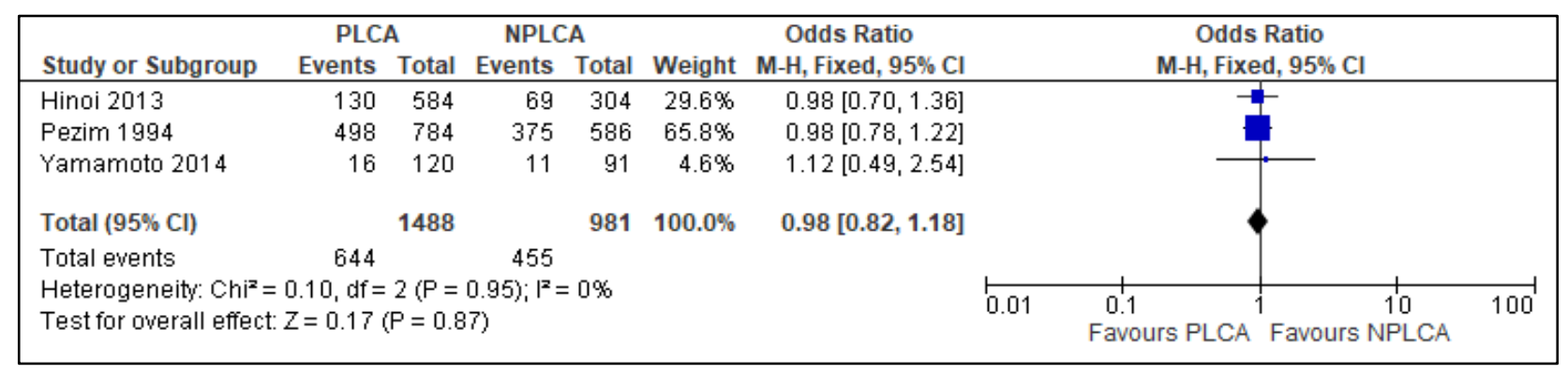

Figure 5: Preserved left colonic artery group versus non preserved left colonic artery, outcome: morbidity.

\begin{tabular}{|c|c|c|c|c|c|c|c|c|c|c|c|}
\hline \multirow[b]{2}{*}{ Study or Subgroup } & \multicolumn{2}{|c|}{ PLCA } & \multicolumn{2}{|c|}{ NPLCA } & \multirow[b]{2}{*}{ Weight } & \multicolumn{2}{|l|}{ Odds Ratio } & \multirow{2}{*}{\multicolumn{3}{|c|}{$\begin{array}{c}\text { Odds Ratio } \\
\text { M-H, Fixed, 95\% Cl }\end{array}$}} & \\
\hline & Events & Total & Events & Total & & M-H, Fixed, $95 \% \mathrm{Cl}$ & & & & & \\
\hline A.zedan 2016 & 4 & 76 & 3 & 38 & $1.4 \%$ & $0.65[0.14,3.06]$ & & & & & \\
\hline Bostrom 2015 & 41 & 388 & 41 & 334 & $14.3 \%$ & $0.84[0.53,1.34]$ & & & $=$ & + & \\
\hline Corder 1992 & 6 & 51 & 12 & 92 & $2.7 \%$ & $0.89[0.31,2.53]$ & & & & & \\
\hline $\operatorname{Han} 2013$ & 5 & 80 & 4 & 71 & $1.4 \%$ & $1.12[0.29,4.33]$ & & & & & \\
\hline Hinoi 2013 & 43 & 584 & 40 & 304 & $17.7 \%$ & $0.52[0.33,0.83]$ & & & $=-$ & & \\
\hline Komen 2011 & 1 & 29 & 7 & 87 & $1.2 \%$ & $0.41[0.05,3.47]$ & & & & & \\
\hline Kwerneng 2017 & 34 & 432 & 22 & 373 & $7.9 \%$ & $1.36[0.78,2.37]$ & & & - & $=$ & \\
\hline Lee 2018 & 0 & 83 & 2 & 51 & $1.1 \%$ & $0.12[0.01,2.52]$ & 4 & & & & \\
\hline Luo 2017 & 17 & 203 & 47 & 320 & $12.2 \%$ & $0.53[0.30,0.95]$ & & & & & \\
\hline Matsuda 2015 & 5 & 49 & 8 & 51 & $2.6 \%$ & $0.61[0.19,2.02]$ & & & & & \\
\hline Rutegard 2012 & 108 & 1101 & 81 & 818 & $30.5 \%$ & $0.99[0.73,1.34]$ & & & - & ⺊ & \\
\hline Rutegard 2016 & 3 & 18 & 1 & 5 & $0.5 \%$ & $0.80[0.06,9.92]$ & & & & & \\
\hline Shen 2014 & 0 & 72 & 2 & 41 & $1.1 \%$ & $0.11[0.01,2.33]$ & $\longleftarrow$ & & & & \\
\hline Tanaka 2015 & 8 & 341 & 0 & 16 & $0.3 \%$ & $0.84[0.05,15.20]$ & & & & & \\
\hline Wang 2015 & 3 & 65 & 5 & 63 & $1.8 \%$ & $0.56[0.13,2.45]$ & & & & - & \\
\hline Yamamoto 2014 & 2 & 120 & 2 & 91 & $0.8 \%$ & $0.75[0.10,5.46]$ & & & & & \\
\hline Yasuda 2016 & 3 & 147 & 2 & 42 & $1.1 \%$ & $0.42[0.07,2.58]$ & & & & & \\
\hline Zhang 2016 & 2 & 46 & 3 & 34 & $1.2 \%$ & $0.47[0.07,2.98]$ & & & & & \\
\hline Total $(95 \% \mathrm{Cl})$ & & 3885 & & 2831 & $100.0 \%$ & $0.79[0.67,0.95]$ & & & 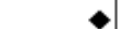 & & \\
\hline \multirow{2}{*}{\multicolumn{7}{|c|}{ 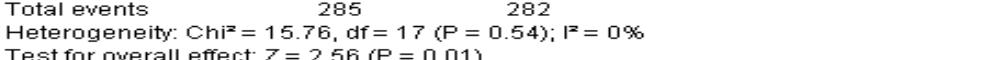 }} & & & & & \\
\hline & & & & & & & 0.01 & $\begin{array}{c}0^{\prime} \cdot 1 \\
\text { Favou }\end{array}$ & Irs PLCA & $\begin{array}{c}10 \\
10 \\
\text { Favours NPLCA }\end{array}$ & 100 \\
\hline
\end{tabular}

Figure 6: Preserved left colonic artery group versus non preserved left colonic artery, outcome: Anastomotic leakage.

\begin{tabular}{|c|c|c|c|c|c|c|c|c|c|c|}
\hline \multirow[b]{2}{*}{ Study or Subgroup } & \multicolumn{2}{|c|}{ PLCA } & \multicolumn{2}{|c|}{ NPLCA } & \multirow[b]{2}{*}{ Weight } & \multirow{2}{*}{$\begin{array}{c}\text { Odds Ratio } \\
\text { M-H, Fixed, } 95 \% \mathrm{Cl}\end{array}$} & \multirow{2}{*}{\multicolumn{4}{|c|}{$\begin{array}{c}\text { Odds Ratio } \\
\text { M-H, Fixed, } 95 \% \mathrm{Cl}\end{array}$}} \\
\hline & Events & Total & Events & Total & & & & & & \\
\hline Adachi 1998 & 22 & 134 & 3 & 38 & $3.3 \%$ & $2.29[0.65,8.12]$ & & & & \\
\hline Bostrom 2015 & 7 & 338 & 9 & 334 & $7.5 \%$ & $0.76[0.28,2.07]$ & & & & \\
\hline Grinnel 1965 & 10 & 181 & 11 & 179 & $8.8 \%$ & $0.89[0.37,2.16]$ & & & & \\
\hline Pezim 1994 & 24 & 784 & 13 & 586 & $12.1 \%$ & $1.39[0.70,2.76]$ & & & & \\
\hline Rosi 1962 & 8 & 154 & 3 & 137 & $2.5 \%$ & $2.45[0.64,9.42]$ & & & & \\
\hline Rutegard 2012 & 16 & 1101 & 13 & 818 & $12.4 \%$ & $0.91[0.44,1.91]$ & & & & \\
\hline slanet 1997 & 58 & 1154 & 47 & 1107 & $38.3 \%$ & $1.19[0.80,1.77]$ & & & & \\
\hline Yamamoto 2014 & 12 & 120 & 7 & 42 & $7.8 \%$ & $0.56[0.20,1.52]$ & & & & \\
\hline Yasuda 2016 & 29 & 147 & 7 & 42 & $7.3 \%$ & $1.23[0.50,3.05]$ & & & & \\
\hline Total $(95 \% \mathrm{Cl})$ & & 4113 & & 3283 & $100.0 \%$ & $1.14[0.89,1.47]$ & & & & \\
\hline Total events & 186 & & 113 & & & & & & & \\
\hline \multicolumn{7}{|c|}{$\begin{array}{l}\text { Heterogeneity: } \mathrm{Chi}^{2}=6.03, \mathrm{df}=8(\mathrm{P}=0.64) ; \mathrm{I}^{2}=0 \% \\
\text { Test for overall effect: } Z=1.07(\mathrm{P}=0.28)\end{array}$} & 0.01 & $\begin{array}{c}0.1 \\
\text { Favours PLCA }\end{array}$ & $\begin{array}{c}10 \\
\text { Favours NPLCA }\end{array}$ & $\overrightarrow{100}$ \\
\hline
\end{tabular}

Figure 7: Preserved left colonic artery group versus non preserved left colonic artery, outcome: Mortality. 


\section{Lymph node harvested}

Four studies reported the number of harvested lymph nodes. After pooling the results, we found no significant difference between the two groups (WMD=0.34, 95\% CI$0.21,0.88, \mathrm{p}=0.23) .{ }^{14,15,17,21}$ No statistical significance was noted. Heterogeneity: $\mathrm{Chi}^{2}=65.44, \mathrm{df}=3 \quad(\mathrm{p}<0.00001)$; $\mathrm{I}^{2}=95 \%$. Test for overall effect: $\mathrm{Z}=1.21(\mathrm{p}=0.23)$. (Figure 4)

\section{Morbidity}

Three studies reported morbidity and there was no significant difference found between the two groups for morbidity $(\mathrm{OR}=0.94,95 \% \mathrm{CI}(0.82,1.18), \mathrm{p}=0.87){ }^{15.20,23}$ No significant heterogeneity was noted; thus, the fixedeffect model was used. Heterogeneity: $\mathrm{Chi}^{2}=0.10, \mathrm{df}=2$ $(\mathrm{p}=0.95) ; \mathrm{I}^{2}=0 \%$. Test for overall effect: $\mathrm{Z}=0.17(\mathrm{p}=0.87)$. (Figure 5)

Three studies reported wound infection and there was no significant difference found between the two groups for wound infection $(\mathrm{OR}=0.84,95 \%$ CI $(0.47,1.51)$, $\mathrm{p}=0.55) .{ }^{15,20,24}$ No significant heterogeneity was noted; thus, the fixed-effect model was used. Heterogeneity: $\mathrm{Chi}^{2}=3.62, \mathrm{df}=2(\mathrm{p}=0.16) ; \mathrm{I}^{2}=45 \%$. Test for overall effect: $\mathrm{Z}=0.59(\mathrm{p}=0.55)$.

\section{Anastomotic leakage}

Eighteen studies reported anastomotic leakage. ${ }^{6,15-22,25-23}$ There was a significant difference between the two groups for anastomotic leakage $(\mathrm{OR}=0.79,95 \% \mathrm{CI}(0.67,0.95)$, $\mathrm{p}=0.01)$. The PLCA group observed less anastomotic leakage compared to NPLCA group. Significant heterogeneity was noted; thus, the fixed-effect model was used Heterogeneity: $\mathrm{Chi}^{2}=15.78, \mathrm{df}=18(\mathrm{p}=0.61) ; \mathrm{I}^{2}=0 \%$. Test for overall effect: $Z=2.55(p=0.01)$. (Figure 6)

\section{Mortality}

Nine studies were collected for mortality and there was no significant difference found between the two groups for mortality $(\mathrm{OR}=1.14,95 \% \mathrm{CI}(0.89,1.47), \mathrm{p}=0.28){ }^{20,23-}$ 25,29,30,34-36 No significant heterogeneity was noted; thus, the fixed-effect model was used. Heterogeneity: $\mathrm{Chi}^{2}=6.03, \mathrm{df}=8(\mathrm{p}=0.64) ; \mathrm{I}^{2}=0 \%$. Test for overall effect: $\mathrm{Z}=1.07(\mathrm{p}=0.28)$ (Figure 7$)$.

\section{Publication bias}

The funnel plot on the anastomotic leakage is shown in figure below. Because all studies laid inside the $95 \%$ CI limits, no evidence of publications bias was noted. Egger test was performed to provide statistical evidence regarding funnel plot symmetry. Result still did not reveal any evidence of publication bias in anastomotic leakage (Heterogeneity: $\mathrm{Chi}^{2}=15.78, \mathrm{df}=18(\mathrm{p}=0.61) ; \mathrm{I}^{2}=0$. (Figure 8)

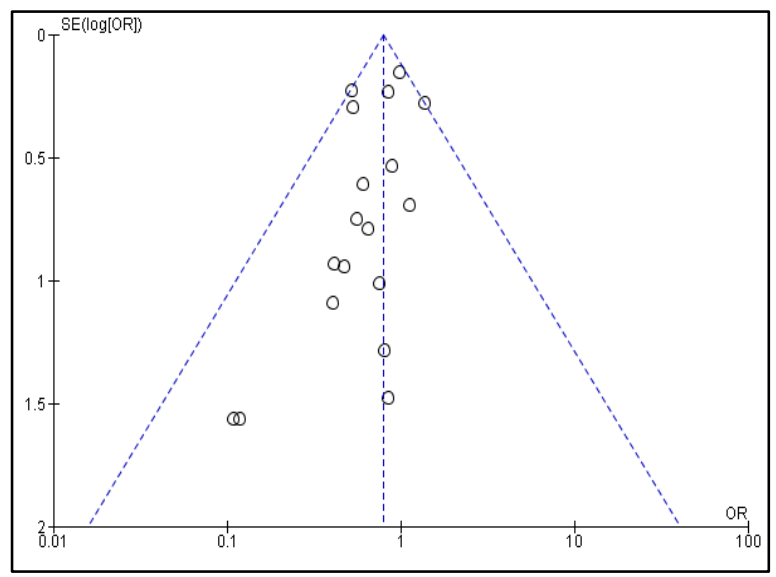

Figure 8: Funnel comparison: preserve versus non preserve left colonic artery: anastomotic leakage.

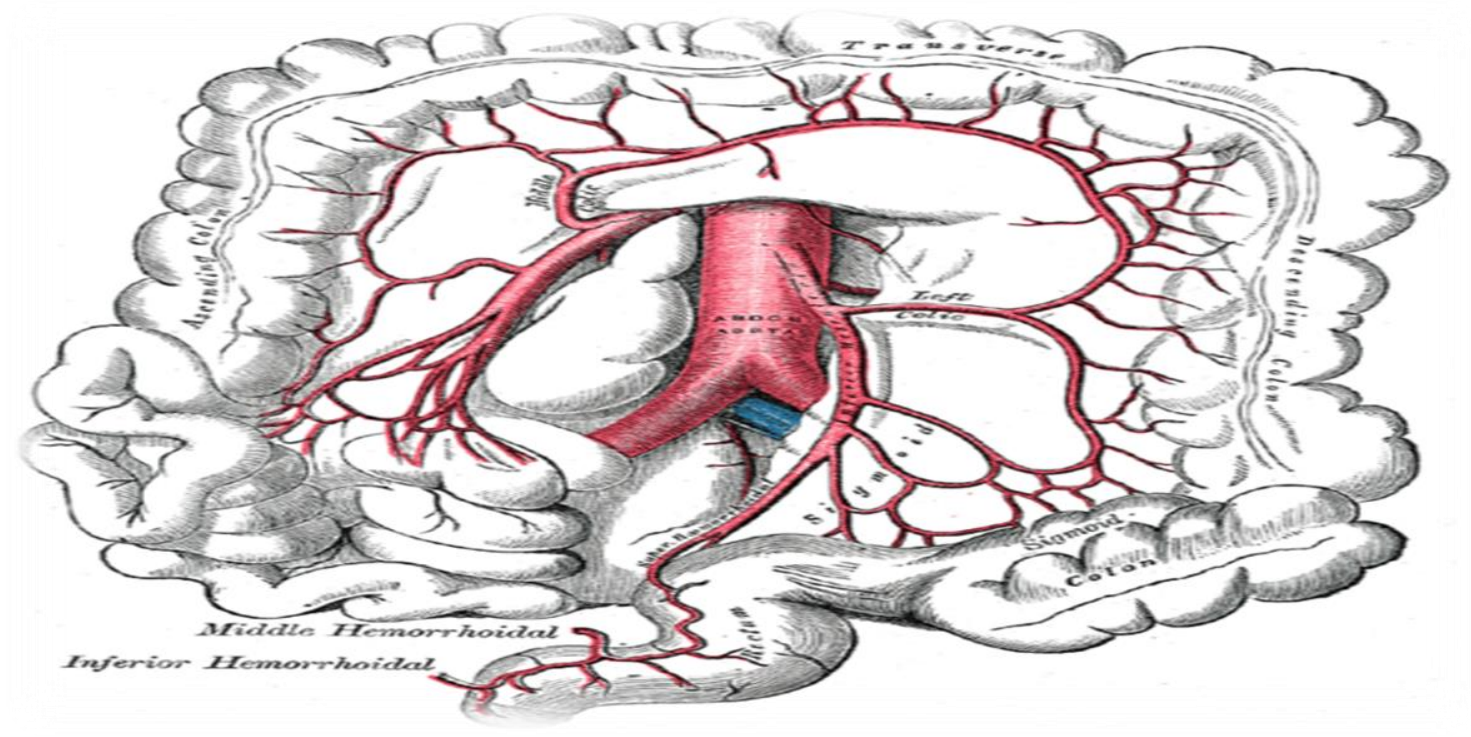

Figure 9: The inferior mesenteric artery and its branches. (Left colic artery visible at center right). 


\section{DISCUSSION}

To date, the discussion of PLCA versus NPLCA persists. This study focuses on the safety and feasibility after PLCA compared to NPLCA. In rectal cancer surgery, the level of IMA ligation has always been debated. ${ }^{6,37-40}$ Although dividing the IMA is a small issue for rectal cancer surgery, there is still no consensus. The optimal ligation level should be demonstrated in light of several considerations, especially in light of oncological outcomes.

Surgical intervention plays a vital role in the survival of patients inflicted with colorectal cancer. But there is not a consensus to the question whether to preserve the LCA or not. According to Lowry et al, preservation of the LCA means low ligation of the IMA, while ligating the LCA means high ligation of the IMA. ${ }^{41}$ Arguments about preserving versus ligating the LCA have existed for at least the last 100 years. The first explanation of this argument was made by Moynihan in 1908 and he argued that ligation and division of the IMA should be flushed with the aorta, which signifies his agreement to ligate the LCA. ${ }^{42}$ Ligating the LCA was thought of to be easy and could decrease the tension of the anastomosis. Collectively, entire pieces of the IMA lymph nodes were removed, assisting in the determination of the stage and prognosis of the cancer. ${ }^{43}$ Kanemitsu et al demonstrated that ligation of the LCA aided in the curative resection and long-term survival in patients with cancer of sigmoid or rectum colon, as well as, nodal metastases at the origin of the IMA. ${ }^{38}$

Our goal of this meta-analysis was to differentiate the preservation of the left colonic artery compared to the nonpreservation left colonic artery related to operative time, blood loss, and lymph node harvest, hospital length of stay, anastomotic leakage, wound infection, morbidity and mortality. Within the studies, anastomotic leakage was the most common occurrence. Taking into account operation time, nine of the included studies had exhibited a much longer operation time in PLCA group than that of NPLCA group (weighted mean difference $(\mathrm{WMD})=9.37 \mathrm{~min}, 95 \%$ CI $(8.92,9.81), \mathrm{p}<0.01)$ and six studies also recorded a significant difference in blood loss, whereby NPLCA observed the least blood loss (weighted mean difference $(\mathrm{WMD})=8.28,95 \%$ CI $(7.43,9.13), \mathrm{p}<0.01) 14,16,19-21$. Yet to come high powered and well-designed random control trials will still be required to examine these issues. However, in regards to lymph node harvest, no significant difference was found in the 2 groups (WMD $=0.34,95 \%$ CI-0.21, 0.88, p=0.23). Recent studies have demonstrated that patients with metastatic lymph nodes above the left colic artery had a poor 5-year disease free survival rate, $31.9 \%$ versus $69.4 \%$ subsequently, in the metastatic and negative IMA lymph nodes groups. ${ }^{44,45}$ The preserved left colonic artery also reported a decreased length in hospital stay over the non-preserved group (WMD $=-2.84,95 \% \mathrm{CI}$ $(-5.49,-0.19), p=0.04)$ in two studies. Noticeably, our studies found a statistically significant difference between the PLCA and NPLCA group in the anastomotic leakage and non-preservation of LCA instead caused more anastomotic leakage. ${ }^{46}$ Anastomosis blood transfusion is the most critical risk factor that influences the anastomotic leakage. ${ }^{47}$ The surgical technique of LCA nonpreservation includes the section of the IMA at its aortic origin to obtain extra length to perform low pelvic anastomosis without tension. However, after the high IMA tie, the distal colon completely depends on the marginal artery arising from the middle colic artery. Although some studies had shown that the marginal artery provided adequate blood supply to the remaining colon, there was not any difference in wound infection and morbidity between the two groups. Nine studies also collected mortality rate and there was no significant difference between the two groups $(\mathrm{OR}=1.14,95 \% \mathrm{CI}(0.89,1.47)$, $\mathrm{p}=0.28$ ) but, explanations of those outcomes may be associated with several factors. Firstly, the extent of lymph node dissection of two groups was equivalent, which indicates that patients in both groups could receive the same radical range of tumor. Secondly, the number of positive lymph nodes was not significantly different between the two groups. The invasion depth of tumor in surgeries can be accurately evaluated during surgeries, combined with postoperative pathological situation, the accuracy in tumor staging will be no different and additional treatment will be the same. Thirdly, previous studies, including this meta-analysis, showed no significant difference in the long-term complications and recurrence rate between the two groups. Hence, we had unequivocal evidence that preservation of the LCA could have the same effect as non-preservation.

It is acknowledged that several limitations and imperfections were encountered throughout this study. First, most studies were retrospective cohort, with few randomized control and prospective studies were available in this field, which may reduce each result's reliability. Second, the limited number of applicable studies may influence the statistical power. Third, the experience and skill of each surgeon likely differed between studies, which would produce certain bias.

\section{CONCLUSION}

In summary, our meta-analysis suggested that preserving the left colonic artery was preferred over not preserving the left colonic artery in terms lower risk of anastomotic leakage and hospital stay duration. The PLCA proves to be safe, feasible and an efficacious technique for patients with colorectal cancer. There was found to be compelling differences between PLCA and NPLCA, NPLCA had less operative time and less blood loss when the operation was done by laparoscopic method unlike PLCA. Nevertheless, in regards to the number of lymph node harvest, wound infection, morbidity and mortality, there was no significant difference between PLCA and NPLCA. However, as there are limitations of this meta-analysis, conclusions should be regarded with some scepticism. 
Funding: This study was supported by the National Science Foundation of China (grant no. 81472334)

Conflict of interest: None declared

Ethical approval: This study was approved by the Regional Ethics of Zhenjiang no. 1 Peoples' Hospital of Jiangsu China (LLYW20190026)

\section{REFERENCES}

1. Ferlay J, Shin HR, Bray F, Forman D, Mathers C, Parkin DMJIjoc. Estimates of worldwide burden of cancer in 2008: GLOBOCAN 2008. 2010;127(12):2893-917.

2. UK CR. Cancer stats monograph 2004. In: Cancer Research UK London; 2004. Accessed on 20 October, 2020.

3. Titu L, Tweedle E, Rooney P. High tie of the inferior mesenteric artery in curative surgery for left colonic and rectal cancers: a systematic review. Digestive surgery. 2008;25(2):148-57.

4. Goligher JJBJoS. The adequacy of the marginal blood-supply to the left colon after high ligation of the inferior mesenteric artery during excision of the rectum. 1954;41(168):351-53.

5. Morgan CN, Griffiths JJS. High ligation of the inferior mesenteric artery during operations for carcinoma of the distal colon and rectum. 1959; 108(6):641-50.

6. Corder A, Karanjia N, Williams J, Heald RJBjos. Flush aortic tie versus selective preservation of the ascending left colic artery in low anterior resection for rectal carcinoma. 1992;79(7):680-82.

7. Hall NR, Finan P, Stephenson B, Lowndes R, Young HJIjocd. High tie of the inferior mesenteric artery in distal colorectal resections - a safe vascular procedure. 1995;10(1):29-32.

8. Dworkin MJ, Allen-Mersh TGJJotACoS. Effect of inferior mesenteric artery ligation on blood flow in the marginal artery-dependent sigmoid colon. 1996;183(4):357-60.

9. Seike K, Koda K, Saito N. Laser Doppler assessment of the influence of division at the root of the inferior mesenteric artery on anastomotic blood flow in rectosigmoid cancer surgery. 2007;22(6):689-97.

10. Siddharth P, Smith NJS. An anatomic basis to prevent ischemia of the colon during operations upon the aorta. 1981;153(1):71-73.

11. Sekimoto M, Takemasa I, Mizushima T. Laparoscopic lymph node dissection around the inferior mesenteric artery with preservation of the left colic artery. 2011;25(3):861-66.

12. Kobayashi M, Okamoto K, Namikawa T, Okabayashi T, Araki K. Laparoscopic lymph node dissection around the inferior mesenteric artery for cancer in the lower sigmoid colon and rectum. Surgical Endoscopy and Other Interventional Techniques. 2006;20(4):563-69.

13. Hozo SP, Djulbegovic B, Hozo IJBmrm. Estimating the mean and variance from the median, range, and the size of a sample. 2005;5(1):13.
14. Guo Y, Wang D, He L. Marginal artery stump pressure in left colic artery-preserving rectal cancer surgery: a clinical trial. ANZ journal of surgery. 2017;87(7-8):576-81.

15. Hinoi T, Okajima M, Shimomura M. Effect of left colonic artery preservation on anastomotic leakage in laparoscopic anterior resection for middle and low rectal cancer. 2013;37(12):2935-43.

16. Komen N, Slieker J, De Kort P. High tie versus low tie in rectal surgery: comparison of anastomotic perfusion. 2011;26(8):1075-78.

17. Lee KH, Kim JS, Kim JYJA. Feasibility and oncologic safety of low ligation of inferior mesenteric artery with D3 dissection in cT3N0M0 sigmoid colon cancer. 2018;94(4):209-15.

18. Matsuda K, Hotta T, Takifuji K. Randomized clinical trial of defaecatory function after anterior resection for rectal cancer with high versus low ligation of the inferior mesenteric artery. 2015;102(5):501-08.

19. Shen J, Li M, Du Y, Qu H, Zhang YJCJMIS. A comparative study of laparoscopic anterior resection of rectal carcinoma with and without preservation of the left colonic artery. 2014;14:22-24.

20. Yamamoto M, Okuda J, Tanaka K, Ishii M, Hamamoto H, Uchiyama KJDs. Oncological impact of laparoscopic lymphadenectomy with preservation of the left colic artery for advanced sigmoid and rectosigmoid colon cancer. 2014;31(6):452-58.

21. Zhang Y, Qu H, Du Y, Xie D, Li M, Shen JJZyxzz. Clinical possibility of low ligation of inferior mesenteric artery and lymph nodes dissection in laparoscopic low anterior resection. 2016;96(24):1916-18.

22. Luo y QJ, Chen JJ. Laparoscopic radical resection of rectal cancer with and without preservation of the left colonic artery: a comparative study. Chin J PractT Suurg. 2017;4.

23. Pezim M, Nicholls RJAos. Survival after high or low ligation of the inferior mesenteric artery during curative surgery for rectal cancer. 1984;200(6):729.

24. Yasuda K, Kawai K, Ishihara S. Level of arterial ligation in sigmoid colon and rectal cancer surgery. 2016;14(1):99.

25. Boström P, Haapamäki M, Matthiessen P, Ljung R, Rutegård J, Rutegård MJCD. High arterial ligation and risk of anastomotic leakage in anterior resection for rectal cancer in patients with increased cardiovascular risk. 2015;17(11):1018-27.

26. Han Y, Lin C, Zhang Z, Xiaohuang TJIJoS. Comparative study on effects of different treatments on inferior mesenteric artery in resection of rectal cancer. 2013;40(11):738-42.

27. Kverneng Hultberg D, Afshar A, Rutegård J. Level of vascular tie and its effect on functional outcome 2 years after anterior resection for rectal cancer. 2017;19(11):987-95.

28. Rutegård M, Hassmén N, Hemmingsson O, Haapamäki MM, Matthiessen P, Rutegård JJSJoS. Anterior resection for rectal cancer and visceral blood flow: an explorative study. 2016;105(2):78-83. 
29. Rutegård M, Hemmingsson $\mathrm{O}$, Matthiessen $\mathrm{P}$, Rutegård JJBjos. High tie in anterior resection for rectal cancer confers no increased risk of anastomotic leakage. 2012;99(1):127-32.

30. Slanetz CA, Grimson RJDotc, rectum. Effect of high and intermediate ligation on survival and recurrence rates following curative resection of colorectal cancer. 1997;40(10):1205-19.

31. Tanaka J, Nishikawa T, Tanaka T. Analysis of anastomotic leakage after rectal surgery: A casecontrol study. Annals of Medicine and Surgery. 2015;4(2):183-86.

32. Wang Q, Zhang C, Zhang H, Wang Y, Yuan Z, Di CJZwcwkzzCjogs. Effect of ligation level of inferior mesenteric artery on postoperative defecation function in patients with rectal cancer. 2015;18(11):1132-35.

33. Zedan AJEJoSO. 300. High or low ligation of the inferior mesenteric artery during curative surgery for rectal cancer. 2016;42(9):S141.

34. Adachi Y, Inomata M, Miyazaki N, Sato K, Shiraishi N, Kitano SJJocg. Distribution of lymph node metastasis and level of inferior mesenteric artery ligation in colorectal cancer. 1998;26(3):179-82.

35. Grinnell RJS. Results of ligation of inferior mesenteric artery at the aorta in resections of carcinoma of the descending and sigmoid colon and rectum. 1965;120:1031-36.

36. Rosi PJSGO. A ten year study of hemicolectomy in the treatment of carcinoma of the left half of the colon. 1962;114:14-24.

37. Hida J-i, Yasutomi M, Maruyama T. Indication for using high ligation of the inferior mesenteric artery in rectal cancer surgery. Diseases of the colon \& rectum. 1998;41(8):984-87.

38. Kanemitsu Y, Hirai T, Komori K, Kato T. Survival benefit of high ligation of the inferior mesenteric artery in sigmoid colon or rectal cancer surgery. British Journal of Surgery: Incorporating European Journal of Surgery and Swiss Surgery. 2006;93(5):609-15.
39. Uehara K, Yamamoto S, Fujita S, Akasu T, Moriya Y. Impact of upward lymph node dissection on survival rates in advanced lower rectal carcinoma. Digestive surgery. 2007;24(5):375-81.

40. Surtees P, Ritchie J, Phillips R. High versus low ligation of the inferior mesenteric artery in rectal cancer. British journal of surgery. 1990;77(6):61821.

41. Lowry AC, Simmang CL, Boulos P. Consensus statement of definitions for anorectal physiology and rectal cancer. Colorectal Disease. 2001;3(4):272-75.

42. Moynihan B. The surgical treatment of cancer of the sigmoid flexure and rectum. Surg Gynecol Obstet. 1908;6:463.

43. Hida J-i, Okuno K. High ligation of the inferior mesenteric artery in rectal cancer surgery. Surgery today. 2013;43(1):8-19.

44. Cirocchi R, Trastulli S, Farinella E. High tie versus low tie of the inferior mesenteric artery in colorectal cancer: a RCT is needed. Surgical oncology. 2012;21(3):e111-23.

45. Kang J, Hur H, Min BS, Kim NK, Lee KY. Prognostic impact of inferior mesenteric artery lymph node metastasis in colorectal cancer. Annals of surgical oncology. 2011;18(3):704-10.

46. Guraya SY. Optimum level of inferior mesenteric artery ligation for the left-sided colorectal cancer: Systematic review for high and low ligation continuum. Saudi medical journal. 2016;37(7):731.

47. Lange MM, Buunen M, van de Velde CJ, Lange JF. Level of arterial ligation in rectal cancer surgery: low tie preferred over high tie. A review. Diseases of the colon \& rectum. 2008;51(7):1139-45.

48. Guo Y, Wang D, He L. Marginal artery stump pressure in left colic artery-preserving rectal cancer surgery: a clinical trial. 2017;87(7-8):576-81.

Cite this article as: Shaibu Z, Chen $\mathrm{Z}$. The difference between preserving and non-preserving left colonic artery for low rectal cancer: a metaanalysis. Int Surg J 2021;8:427-35. 